\begin{tabular}{|c|l|}
\hline Title & $\begin{array}{l}\text { The efficacy of the well of the well (WOW) culture system on development of bovine embry os in a small group and the } \\
\text { effect of number of adjacent embryos on their development. }\end{array}$ \\
\hline Author(s) & $\begin{array}{l}\text { Kang, Sung-Sik; Ofuji, Sosuke; Imai, Kei; Huang, Weiping; Koyama, Keisuke; Y anagawa, Yojiro; Takahashi, } \\
\text { Yoshiyuki; Nagano, Masashi }\end{array}$ \\
\hline Citation & $\begin{array}{l}\text { Zygote, 23(3), 412-415 } \\
\text { https://doi.org/40.1017/S096719941400001X }\end{array}$ \\
\hline Issue Date & 201405 \\
\hline Doc URL & http://hdl.handle.net/2115/56333 \\
\hline Rights & ○ Cambridge University Press 2014 \\
\hline Type & article \\
\hline File Information & Zygote nagano.M.pdf \\
\hline
\end{tabular}

Instructions for use 


\title{
The efficacy of the well of the well (WOW) culture system on development of bovine embryos in a small group and the effect of number of adjacent embryos on their development
}

\author{
Sung-Sik Kang ${ }^{2}$, Sosuke Ofuji ${ }^{2}$, Kei Imai ${ }^{3,5}$, Weiping Huang ${ }^{2}$, Keisuke Koyama ${ }^{2}$, Yojiro Yanagawa ${ }^{2}$, \\ Yoshiyuki Takahashi ${ }^{2,4}$ and Masashi Nagano ${ }^{1}$ \\ Laboratory of Theriogenology, Department of Veterinary Clinical Sciences, Graduate School of Veterinary Medicine, \\ Hokkaido University, Sapporo; National Livestock Breeding Center, Nishigo, Fukushima; and Genetics Hokkaido \\ Association, Sapporo, Japan
}

Date submitted: 30.09.2013. Date revised: 23.12.2013. Date accepted: 27.12.2013

\section{Summary}

\begin{abstract}
The aim of the present study was to clarify the efficacy of the well of the well (WOW) culture system for a small number of embryos and the effect of number of adjacent embryos in a WOW dish on blastocyst development. In conventional droplet culture, embryos in the small-number group (5-6 embryos/droplet) showed low blastocyst development compared with a control group (2526 embryos/droplet). However, small and large numbers of embryos (5-6 and 25 embryos, respectively) in a WOW dish showed no significant differences in cleavage, blastocyst rates, and mean cell number in blastocysts compared with the control group (25-30 embryos/droplet). In addition, the number of adjacent embryos in a WOW dish did not affect the development to blastocysts and cell number in blastocysts. In conclusion, a WOW dish can provide high and stable blastocyst development in small group culture wherever embryos are placed in microwells of the WOW dish.
\end{abstract}

Keywords: Bovine, Embryonic Development, Droplet, IVC, WOW

\section{Introduction}

During recent decades, assisted reproductive technologies in cattle have achieved considerable advances, such as a combination of in vitro embryo production (IVP) and ovum pick-up (OPU). An average of four to six available oocytes from a single cow are collected by OPU or a single slaughtered valuable oocyte donor

\footnotetext{
${ }^{1}$ All correspondence to: M. Nagano. Laboratory of Theriogenology, Department of Veterinary Clinical Sciences, Graduate School of Veterinary Medicine, Hokkaido University, Kita-ku Kita 18 Nishi 9, Sapporo 060-0818, Japan. Tel:/Fax: +81 11706 5231. e-mail: mnaga@vetmed.hokudai. ac.jp

${ }^{2}$ Institute: Laboratory of Theriogenology, Department of Veterinary Clinical Sciences, Graduate School of Veterinary Medicine, Hokkaido University, Sapporo 060-0818, Japan.

${ }^{3}$ National Livestock Breeding Center, Nishigo, Fukushima 961-8511, Japan.

${ }^{4}$ Genetics Hokkaido Association, Sapporo 060-0040, Japan.

${ }^{5}$ Present address: College of Agriculture, Food and Environment Sciences, Department of Sustainable Agriculture, Rakuno Gagkuen University, Ebetsu-shi 069-8501, Japan.
}

cow (Hasler, 1998; Merton et al., 2009). However, most laboratories currently culture up to 20 embryos in a 20-50- $\mu 1$ droplet or up to 50 embryos in 400-500 $\mu$ in a well in vitro (Krisher \& Wheeler, 2010; Vajta, 2010) to obtain transferrable embryos. Small groups of 110 embryos in a droplet or a well have been shown to have low blastocyst rate and quality compared with large groups of 20-25 embryos (Donnay et al., 1997; Ikeda et al., 2000; Nagao et al., 2008; Senatore et al., 2010; Ward et al., 2000; Vajta et al., 2000). Therefore, a culture system for a small group of embryos is required to improve blastocyst yield. It has been reported that, if embryos were cultured in a custom-made microwell in a large well (WOW) (Vajta et al., 2000; Matoba et al., 2010) and in a commercially available polystyrenebased WOW (25 microwells) (Sugimura et al., 2010), the blastocyst rate was significantly higher than that of droplet culture. In addition, Sugimura et al. (2013) demonstrated that the blastocyst rate in small-group culture (five embryos) in a WOW was higher than in a droplet.

Gopichandran \& Leese (2006) reported that embryos surrounded by three or eight adjacent embryos 
showed low blastocyst development compared with those surrounded by five adjacent embryos when bovine embryos were cultured in a group in a droplet. It was also reported that the number of adjacent embryos (three, five, or eight) did not affect blastocyst development in a custom-made WOW dish (Matoba et al., 2010). This discrepancy may have been caused by the large depth $(500 \mu \mathrm{m})$ of microwells of custommade WOW dishes (Matoba et al., 2010) because the overall diameter of embryos ranges from 150-190 $\mu \mathrm{m}$ (Linder \& Wright, 1983). It is thought that usage of a commercially available WOW dish is preferable to achieve a high and stable blastocyst rate for culturing a small number of embryos. However, an embryo in a microwell (169 $\mu \mathrm{m}$ in depth) in the WOW dish developed by Sugimura et al. (2010) can be affected by factors outside of the microwell. Thus, we should examine the effect of the number of adjacent embryos on blastocyst production by a commercially available WOW dish.

In the present study, we examined the effects of the total number of embryos (five versus 25 embryos) and the number of adjacent embryos (zero, three, five, and eight embryos) in a WOW dish on blastocyst development.

\section{Materials and methods}

All the chemicals used for this study were purchased from Sigma-Aldrich (St. Louis, MO, USA), unless otherwise stated.

In vitro maturation (IVM) of bovine oocytes was performed as described previously (Takahashi et al., 1996). In brief, cumulus-oocyte complexes (COCs) aspirated from follicles (2-8 $\mathrm{mm}$ in diameter) of slaughterhouse-derived ovaries were cultured for $22 \mathrm{~h}$ in a droplet (about 10 COCs $/ 50 \mu \mathrm{l}$ ) of maturation medium under a humidified atmosphere of $5 \% \mathrm{CO}_{2}$ in air at $39{ }^{\circ} \mathrm{C}$. Maturation medium consisted of HEPESbuffered TCM-199 (Invitrogen, Grand Island, NY, USA) supplemented with $10 \%$ fecal calf serum (FCS; Invitrogen), $0.2 \mathrm{mM}$ sodium pyruvate, 0.02 units $/ \mathrm{ml}$ follicle-stimulating hormone, $1 \mu \mathrm{g} / \mathrm{ml}$ estradiol- $17 \beta$, and $50 \mu \mathrm{g} / \mathrm{ml}$ gentamicin sulfate.

In vitro fertilization (IVF) was conducted according to a procedure described previously (Takahashi \& Kanagawa, 1998). Briefly, after the thawing of frozen semen, motile sperm were separated using a Percoll gradient (45 and 90\%). COCs were co-incubated with motile sperm $\left(5 \times 10^{6}\right.$ cells $\left./ \mathrm{ml}\right)$ in droplets $(10-$ 13 COCs $/ 100 \mu \mathrm{l}$ ) of modified Brackett and Oliphant's isotonic medium (Takahashi \& First, 1992) containing $3 \mathrm{mg} / \mathrm{ml}$ fatty acid-free bovine serum albumin (BSA) and $2.5 \mathrm{mM}$ theophylline for $18 \mathrm{~h}$ at $39{ }^{\circ} \mathrm{C}$ under a humidified atmosphere of $5 \% \mathrm{CO}_{2}, 5 \% \mathrm{O}_{2}$, and $90 \% \mathrm{~N}_{2}$.

\section{In vitro culture of presumptive zygotes}

In vitro culture (IVC) of presumptive zygotes was performed using the procedures that were basically the same as described previously (Takahashi \& Kanagawa, 1998). After co-incubation with sperm, presumptive zygotes freed from cumulus cells by vortexing were washed three times and cultured for $150 \mathrm{~h}$ in droplets or a WOW dish using a modified synthetic oviduct fluid medium that contained $1 \mathrm{mM}$ glutamine, 12 essential amino acids for basal medium Eagle, seven non-essential amino acids for minimum essential medium, $10 \mu \mathrm{g} / \mathrm{ml}$ insulin, $5 \mathrm{mM}$ glycine, $5 \mathrm{mM}$ taurine and $1 \mathrm{mM}$ glucose (Takahashi \& Kanagawa, 1998), and added $3 \mathrm{mg} / \mathrm{ml}$ fatty acid-free BSA instead of polyvinyl alcohol at $39^{\circ} \mathrm{C}$ under $5 \% \mathrm{CO}_{2}, 5 \% \mathrm{O}_{2}$ and $90 \% \mathrm{~N}_{2}$. Polystyrene-based WOW dishes that have 25 microwells $(5 \times 5$ microwells with $170-\mu \mathrm{m}$ depth, 290- $\mu \mathrm{m}$ diameter, and 400- $\mu \mathrm{m}$ distance between them; Dai Nippon Printing Co. Ltd., Tokyo, Japan) were prepared as described previously (Sugimura et al., 2010). In brief, $125 \mu \mathrm{l}$ of culture medium were placed within the circular wall of WOW dish that contained microwells and covered with paraffin oil (Nacalai Tesque, Inc., Kyoto, Japan). Twenty-five embryos were placed individually in each microwell in a WOW dish. For the culturing of five embryos, four embryos were placed in the microwell of four corners and the remaining one was put into the center microwell in a WOW dish (no adjacent embryo).

To examine the effect of embryo number in a droplet and a WOW dish on the development to blastocysts, small or large numbers of embryos (5-6 or 25-26, respectively) inseminated by bull A sperm were cultured in a 40- $\mu 1$ droplet. Another large number of embryos inseminated by bull B sperm were cultured in a droplet (25-30 embryos/30 $\mu \mathrm{l})$, and five or 25 embryos were cultured in a WOW. The effect of the number of adjacent embryos in a WOW was examined using data of the five-embryo culture (no adjacent embryos; Fig. $1 A$ ) and the 25-embryo culture with different numbers of adjacent embryos (three, five, and eight embryos; Fig. 1B). Cleavage and blastocyst rates were assessed after $30 \mathrm{~h}$ and $150 \mathrm{~h}$ of IVC, respectively. All embryos that developed to blastocysts were subjected to counting of their cell numbers using an air-drying method (Takahashi \& First, 1992).

\section{Statistical analysis}

The frequencies of cleavage and development to blastocysts, and cell numbers in blastocysts were compared by one-way analysis of variance (ANOVA) followed by Tukey-Kramer's honestly significant difference (HSD) test as the post hoc test. Proportions of blastocysts among the embryo groups placed in different positions of a WOW dish (different numbers of 


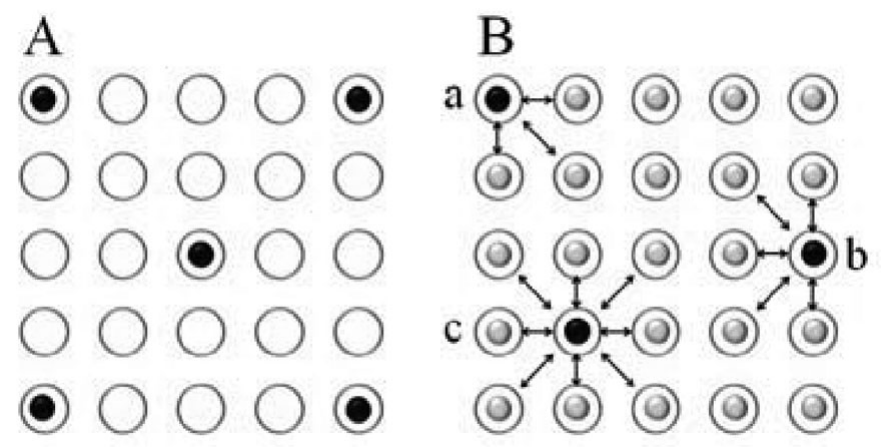

Figure 1 Different numbers of adjacent embryos in 25 microwells in a WOW dish.

$(A)$ Embryo with no adjacent embryos. $(B)$ a: Embryo with three adjacent embryos; b: embryo with five adjacent embryos; c: embryo with eight adjacent embryos.

Table 1 Effect of embryo number in a droplet and a WOW dish on embryonic development

\begin{tabular}{ccccccc}
\hline Bull & Culture system & $\begin{array}{c}\text { No. of embryos } \\
\text { cultured }\end{array}$ & $\begin{array}{c}\text { No. of embryos } \\
\text { (replicates) }\end{array}$ & Cleaved (\%) & Blastocysts (\%) & $\begin{array}{c}\text { Mean cell numbers in } \\
\text { blastocysts }(n)\end{array}$ \\
\hline A & Droplet & $25-26$ & $102(4)$ & $85.4 \pm 7.8$ & $38.3 \pm 1.7$ & $186.1 \pm 63.5^{a}(39)$ \\
& Droplet & $5-6$ & $97(4)$ & $71.0 \pm 15.0$ & $28.8 \pm 8.5$ & $142.1 \pm 64.1^{b}(28)$ \\
& Droplet & $25-30$ & $197(7)$ & $87.8 \pm 4.4$ & $41.2 \pm 8.4$ & $1660 \pm 59.9(82)$ \\
B & WOW & 5 & $75(3)$ & $89.3 \pm 10.1$ & $41.3 \pm 12.2$ & $147.0 \pm 56.7(31)$ \\
& WOW & 25 & $100(4)$ & $82.0 \pm 5.2$ & $45.0 \pm 8.9$ & $151.9 \pm 45.7(45)$ \\
\hline
\end{tabular}

${ }^{a, b}$ Values (means \pm standard deviation (SD)) with different superscripts differ significantly $(P<0.01)$.

Table 2 Effect of the number of adjacent embryos (position of embryos) in a WOW on the development of embryos to blastocysts and their cell numbers

\begin{tabular}{lcccc}
\hline $\begin{array}{l}\text { No. of cultured } \\
\text { embryos in a WOW }\end{array}$ & $\begin{array}{c}\text { No. of adjacent } \\
\text { embryos }\end{array}$ & No. of embryos & Blastocysts $(n)$ & $\begin{array}{c}\text { Mean cell numbers in } \\
\text { blastocysts }(n)\end{array}$ \\
\hline 25 & 8 & 36 & $41.7(15)$ & $151.3 \pm 44.1(15)$ \\
5 & 5 & 48 & $47.9(23)$ & $150.9 \pm 46.8(23)$ \\
& 3 & 16 & $43.8(7)$ & $156.6 \pm 52.1(7)$ \\
& 0 & 75 & $41.3(31)$ & $147.0 \pm 56.7(31)$ \\
\hline
\end{tabular}

Data were pooled from four replicates of culture of 25 embryos and three replicates of culture of five embryos with WOW (bull B) in Table 1.

Cell numbers in blastocysts are means \pm standard deviation (SD).

adjacent embryos) were compared by chi-squared test. All analysis was performed using JMP Pro software (version 10.0.2, SAS Institute, Cary, NC, USA).

\section{Results}

As shown in Table 1, when embryos were cultured in a droplet, cleavage and blastocyst rates of the largenumber group (25-26 embryos/droplet) tended to be higher than those of the small-number group (56 embryos/droplet) $(P=0.14$ and 0.07 , respectively). In addition, the total cell number in blastocysts of the large-number group was significantly higher than that of the small-number group $(P<0.01)$. When embryos were cultured in WOW, blastocyst rates were high regardless of embryo number in the WOW dish and similar to that of the large-number group in a droplet. Furthermore, the number of adjacent embryos in a WOW dish did not affect the development to blastocysts and total cell numbers in blastocysts, as shown in Table 2.

\section{Discussion}

Culture of small numbers of embryos in a droplet reduced the blastocyst rate and the quality of blastocysts (mean cell numbers in blastocysts) compared with those for embryos cultured with large numbers of embryos in a droplet (Nagao et al., 2008; Senatore et al., 2010). In the present study, there was no reduction in blastocyst rate and quality in a WOW dish. This result is in agreement with previous findings 
that the development of embryos to blastocysts was independent of the total number of embryos in a WOW dish (Sugimura et al., 2013). We speculated that diffusible factors such as autocrine/paracrine growth factors released by embryos can be diffused in a droplet and influence the growth of their adjacent embryos (Stokes et al., 2005). A small amount of autocrine/paracrine factors may be secreted by a small number of embryos, would be easily diluted in a droplet, and would show few effects on embryonic development. However, in this WOW dish, diffusible factors secreted by individual embryos probably accumulated in a microwell, which may provide a suitable microenvironment for their development, as suggested in a previous study (Swain \& Smith, 2011). Moreover, adjacent embryos in a WOW dish also did not affect blastocyst development and mean cell numbers in blastocysts in the present study, as previously described (Matoba et al., 2010), even though the depth of the microwell was different.

In conclusion, the polystyrene-based WOW dish used in this study is effective for individual embryo culture of small groups, and there is no reduction in embryo development, regardless of the number of adjacent embryos (position of embryos) in microwells of the WOW.

\section{Acknowledgements}

We thank Genetics Hokkaido Association for the donation of frozen bull sperm.

\section{References}

Donnay, I., Van Langendonckt, A., Auquier, P., Grisart, B., Vansteenbrugge, A., Massip, A. \& Dessy, F. (1997). Effects of co-culture and embryo number on the in vitro development of bovine embryos. Theriogenology 47, 154961.

Gopichandran, N. \& Leese, H.J. (2006). The effect of paracrine/autocrine interactions on the in vitro culture of bovine preimplantation embryos. Reproduction 131, 26977.

Hasler, J.F. (1998). The current status of oocytes recovery, in vitro embryo production, and embryo transfer in domestic animals, with an emphasis on the bovine. J. Anim. Sci. 76, 52-74.

Ikeda, K., Takahashi, Y. \& Katagiri, S. (2000). Effect of medium change on the development of in vitro matured and fertilized bovine oocytes cultured in medium containing amino acids. J. Vet. Med. Sci. 62, 121-3.

Krisher, R.L. \& Wheeler, M.B. (2010). Towards the use of microfluidics for individual embryo culture. Reprod. Fertil. Dev. 22, 32-9.

Linder, G.M. \& Wright, R.W. Jr. (1983). Bovine embryo morphology and evaluation. Theriogenology 20, 407-16.

Matoba, S., Fair, T. \& Lonergan, P. (2010). Maturation, fertilisation and culture of bovine oocytes and embryos in an individually identifiable manner: a tool for studying oocyte developmental competence. Reprod. Fertil. Dev. 22, 839-51.

Merton, J.S., Ask, B., Onkundi, D.C., Mullaart, E., Colenbrander, B. \& Nielen, M. (2009). Genetic parameters for oocyte number and embryo production within a bovine ovum pick-up-in vitro production embryoproduction program. Theriogenology 72, 885-93.

Nagao, Y., Iijima, R. \& Saeki, K. (2008). Interaction between embryos and culture conditions during in vitro development of bovine early embryos. Zygote 16, 12733.

Senatore, E.M., Xu, J., Suárez Novoa, M.V., Gong, G., Lin, T., Bella, A., Moreno, J.F., Mannino, M.E., Tian, X., Presicce, G.A., Wu, S.-C. \& Du, F. (2010). Improved in vitro development of OPU-derived bovine (Bos taurus) embryos by group culture with agarose-embedded helper embryos. Theriogenology 74, 1643-51.

Stokes, P. J., Abeydeera, L. R. \& Leese, H. J. (2005). Development of porcine in vivo and in vitro; evidence for embryo 'cross talk' in vitro. Dev. Biol. 284, 62-71.

Sugimura, S., Akai, T., Somfai, T., Hirayama, M., Aikawa, Y., Ohtake, M., Hattori, H., Kobayashi, S., Hashiyada, Y., Konishi, K. \& Imai, K. (2010). Time lapse cinematographycompatible polystyrene-based microwell culture system: A novel tool for the development of individual bovine embryos. Biol. Reprod. 83, 970-8.

Sugimura, S., Akai, M., Hashiyada, Y., Aikawa, Y., Ohtake, M., Matsuda, H., Kobayashi, S., Kobayashi, E., Konishi, K. \& Imai, K. (2013). Effect of embryo density on in vitro development and gene expression in bovine in vitro-fertilized embryos cultured in a microwell system. J. Reprod. Dev. 59, 115-22.

Swain, J.E. \& Smith, G.D. (2011). Advances in embryo culture platforms: novel approaches to improve preimplantation embryo development through modifications of the microenvironment. Hum. Reprod. Update 17, 54157.

Takahashi, Y. \& First, N.L. (1992). In vitro development of bovine one-cell embryos: influence of glucose, lactate, pyruvate, animo acids and vitamins. Theriogenology 37, 963-78.

Takahashi, Y. \& Kanagawa, Y. (1998). Effects of glutamine, glycine and taurine on the development of in vitro fertilized bovine zygotes in a chemically defined medium. J. Vet. Med. Sci. 60, 433-7.

Takahashi, Y., Hishinuma, M., Matsui, M., Tanaka, H. \& Kanagawa, H. (1996). Development of in vitro matured/fertilized bovine embryos in a chemically defined medium: influence of oxygen concentration in the gas atmosphere. J. Vet. Med. Sci. 58, 897-902.

Vajta, G. (2010). Embryo culture: can we perform better than nature?. Reprod. Biomed. Online 20, 453-69.

Vajta, G., Peura, T.T., Holm, P., Paldi, A., Greve, T., Trounson, A.O. \& Challensen, H. (2000). New method for culture of zona-included or zona-free embryos: the well of the well (WOW) system. Mol. Reprod. Dev. 55, 256-64.

Ward, F. A., Lonergan, P., Enright, B. P. \& Boland, M. P. (2000). Factors affecting recovery and quality of oocytes for bovine embryo production in vitro using ovum pickup technology. Theriogenology 54, 433-46. 